\title{
Application of the Hybrid-Maize model for limits to maize productivity analysis in a semiarid environment
}

Yi Liü ${ }^{1,2}$, Shenjiao Yang ${ }^{2,3}$, Shiqing $\mathrm{Li}^{2}$, Fang Chen ${ }^{1}$ *

\author{
${ }^{1}$ Chinese Academy of Sciences/Wuhan Botanical Garden - \\ Lab. of Aquatic Botany and Watershed Ecology - 430074 \\ - Wuhan - China. \\ ${ }^{2}$ Chinese Academy of Sciences and Ministry of Water \\ Resource/Institute of Soil and Water Conservation - State \\ Key Lab. of Soil Erosion and Dryland Farming on the Loess \\ Plateau - 712100 - Yangling - China. \\ ${ }^{3}$ Chinese Academy of Agricultural Sciences/Farmland \\ Irrigation Research Institute - 453003 - Xinxiang - China. \\ *Corresponding author <fchen@ipni.ac.cn>
}

Edited by: Thomas Kumke

Received September 14, 2011

Accepted February 14, 2012

\begin{abstract}
Effects of meteorological variables on crop production can be evaluated using various models. We have evaluated the ability of the Hybrid-Maize model to simulate growth, development and grain yield of maize (Zea mays L.) cultivated on the Loess Plateau, China, and applied it to assess effects of meteorological variations on the performance of maize under rain-fed and irrigated conditions. The model was calibrated and evaluated with data obtained from field experiments performed in 2007 and 2008, then applied to yield determinants using daily weather data for 2005-2009, in simulations under both rain-fed and irrigated conditions. The model accurately simulated Leaf Area Index, biomass, and soil water data from the field experiments in both years, with normalized percentage root mean square errors $<25 \%$. Gr.Y and yield components were also accurately simulated, with prediction deviations ranging from $-2.3 \%$ to $22.0 \%$ for both years. According to the simulations, the maize potential productivity averaged $9.7 \mathrm{tha}^{-1}$ under rain-fed conditions and $11.53 \mathrm{t} \mathrm{ha}^{-1}$ under irrigated conditions, and the average rain-fed yield was $1.83 \mathrm{tha}^{-1}$ less than the average potential yield with irrigation. Soil moisture status analysis demonstrated that substantial potential yield may have been lost due to water stress under rain-fed conditions.

Keywords: crop simulation, maize model, potential productivity, water stress, spring maize
\end{abstract}

\section{Introduction}

Maize (Zea mays L.) has become a major crop on the Loess Plateau, China, in the last ten years, and now covers ca. 27.3 of the agricultural area in the region (Xue et al., 2008). The increase of its cultivation has been prompted by agricultural advances, such as improvements in crop rotations in conjunction with improvements in uses of agricultural equipment and human resources, and increases in maize prices (Xue et al., 2008). However, the area is mostly located in a semiarid region of China, where the annual precipitation ranges from $150-300 \mathrm{~mm}$ in the north to $500-700 \mathrm{~mm}$ in the south (Li and Xiao, 1992), and water availability for crop production is often sub-optimal due to both overall shortages and uneven distributions of water supplies during the year. Hence, drought has long been the primary factor limiting crop production in the area (Kang et al., 2002; Wang et al., 2009; Zhang et al., 2009). However, there is a lack of robust information regarding effects of meteorological variations on maize yields, although there has been some investigation of their effects during the maize growing season (Liu et al., 2010a, b).

Sharply rising global demands for biofuel (in conjunction with continuing increases in food and feed requirements) are expected to lead to further substantial increases in maize production (Cassman et al., 2003), but potential maize yields have increased little in the last three decades (Duvick and Cassman, 1999; Tollenaar and Lee, 2002). Any crop productivity is directly related to its uptake of resources, e.g. light and water, and its efficiency of utilizing them to generate biomass (Azam-Ali et al., 1994; Yang et al., 2004; Liu et al., 2010a). Analyses of relationships between potential maize yields and environmental factors have shown that light, temperature and water availability are crucial yield determinants (Cirilo and Andrade, 1994).

Several authors have attempted to quantify yield potential and its variation at a regional scale using both observed data (Duncan et al., 1973) and modeling (Muchow et al., 1990; Löffler et al., 2005; Tojo Soler et al., 2007; Grassini et al., 2009). The models used, e.g. CROPGRO and CERES have deficiencies in simulating maize production (Sadler et al., 2000), despite continuing attempts to improve them and extend their range of applicability (Pedersen et al., 2004; Sau et al., 2004; Lizaso et al., 2001). However, in all of the cited studies, yield of maize crops have been evaluated using mean values of meteorological variables for full growing seasons, rather than during specific growth phases when crops are most strongly affected by environmental factors. In addition, the applied practices may not have been optimal for maximizing yields at the study sites in some cases. Nevertheless, maize yields (measured and simulated) seem to be substantially lower than potential yields (Grassini et al., 2009).

The Hybrid-Maize model (Yang et al., 2004, 2006) is a process-based model for simulating the development and growth of maize with daily time steps, assuming no growth limitations due to nutrient deficiency, toxicity, diseases, insect pests or weeds. It incorporates functions simulating: temperature effects of maize development; photosynthesis (in vertically integrated canopy layers); growth-related, organ-specific respiration; and temperature-dependent maintenance respiration. Due to the inclusion of photosynthesis and respiration (growth and 
maintenance) the model may be more sensitive to variations in environmental conditions than other models, e.g. CERES-Maize (Jones and Kiniry, 1986; Jones et al., 2003), and the Muchow-Sinclair-Bennett model (Muchow et al., 1990), which utilize radiation-use efficiency to integrate effects of assimilation and respiration processes. Therefore, to address gaps in knowledge regarding maize productivity and its variability, we used the Hybrid-Maize model (Yang et al., 2004) to assess limits of maize total aboveground biomass (tDM) production and grain yield (Gr.Y) on the Loess Plateau. The primary objectives were to: (i) evaluate the performance of the Hybrid-Maize model for simulating maize growth, development, and yield on the Loess Plateau; (ii) to apply the model to evaluate the impact of meteorological variables on maize yield under irrigated and rain-fed conditions.

\section{Materials and Methods}

\section{Field experiment design}

Data used to evaluate and apply the model were acquired from field experiments at sites on flat farmland in 2007 and 2008 at the Changwu Agriecological Station $\left(35.2^{\circ} \mathrm{N}, 107.8^{\circ} \mathrm{E}, 1,200 \mathrm{~m}\right.$ above sea level), on the Loess Plateau, Shaanxi Province, China. The station is located in the Changwu tableland-gully region on the southern part of the Loess Plateau, northwest China (Figure 1). The average annual precipitation from 1990 to 2008 was $578 \pm 69 \mathrm{~mm}$, with $55 \%$ falling between July and September, and the annual average temperature $9.1 \pm 2.3^{\circ} \mathrm{C}$. According to the Chinese Soil Taxonomy, the soils are Cumuli-Ustic Isohumosols, and contained $300 \mathrm{~g} \mathrm{~kg}^{-1}$ clay, $660 \mathrm{~g} \mathrm{~kg}^{-1}$ silt and $40 \mathrm{~g} \mathrm{~kg}^{-1}$ sand with a gravimetric field capacity of $22 \%$, wilting point of $8 \%$, and stable water content of $15 \%$. The main soil physical and chemical properties $(0-20 \mathrm{~cm}$ depth) of the site are as follows: bulk density $1.30 \mathrm{~g} \mathrm{~cm}^{-3}, \mathrm{pH} 8.4$, organic matter $11.8 \mathrm{~g} \mathrm{~kg}^{-1}$, total nitrogen $0.87 \mathrm{~g} \mathrm{~kg}^{-1}$, inorganic nitrogen $3.15 \mathrm{mg} \mathrm{kg}^{-1}$, available phosphorus $14.4 \mathrm{mg} \mathrm{kg}^{-1}$ available potassium $144.6 \mathrm{mg} \mathrm{kg}^{-1}$. In most of the region,

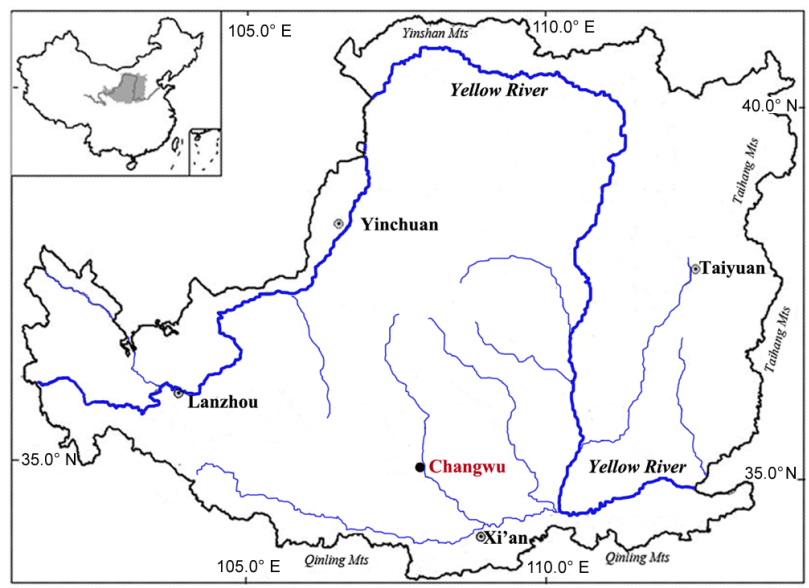

Figure 1 - Location of Changwu Agro-ecological Experiment Station. a single wheat or maize crop is produced per year, by rain-fed agriculture.

Two experimental treatments were applied in this study. In one, designated "rain-fed", the only water supplied to the crops was natural rainfall. In the other, designated "irrigated", furrow irrigation (using tap water) was applied to maintain the water content of the soil at 70-85 $\%$ of field capacity by raising it to $85 \%$ whenever it fell below $70 \%$. The field was irrigated in this manner with irrigation depths, on each occasion, of $33.7 \mathrm{~mm}$. These treatments were applied to plots measuring $7.8 \mathrm{~m} \times 6.5$ $\mathrm{m}$, with four replicates. The maize used in the experiment was 'pioneer 335 ', a spring cultivar that is widely used by farmers in the region. Following a base fertilizer dose of nitrogen (110 $\mathrm{kg} \mathrm{ha}^{-1}$ ), phosphorus (50 kg ha-1), and potassium (100 $\left.\mathrm{kg} \mathrm{ha}^{-1}\right)$, the maize was sown in 5 $\mathrm{cm}$ holes spaced $20 \mathrm{~cm}$ apart in rows spaced $60 \mathrm{~cm}$ apart on April 20 in both years. Water $(300 \mathrm{~mL})$ was poured into each seed hole before backfilling, to promote germination and seedling emergence. Additional nitrogen, in the form of urea, was applied using a hole-sowing machine in the furrows at the jointing and tasseling stages, at rates of $80 \mathrm{~kg} \mathrm{~N} \mathrm{ha}^{-1}$ and $90 \mathrm{~kg} \mathrm{~N} \mathrm{ha}^{-1}$, respectively, following a nutrient management plan aimed to achieve a final maize yield of $14 \mathrm{tha}^{-1}$.

\section{Sampling and measurements}

During vegetative stages, the phenological development of the maize was monitored by: counting daily leaf collars; recording silking when silks extended beyond the husks of half the plants in each plot; and determining physiological maturity, defined by "the presence of black layers at the base of the grains" (Tojo Soler et al., 2007), by sampling five cobs in each plot regularly. In addition, estimates of aboveground biomass and leaf area were obtained by harvesting plants from $1 \mathrm{~m}$ of the central row of each plot at the $6^{\text {th }}$ leaf, $12^{\text {th }}$ leaf, silking and milk stages, the dough stage (in 2008, but not 2007), and physiological maturity. The areas used for sampling on each occasion were spaced in order to avoid sampling plants that may have been affected by earlier samplings. The width and length of each collected leaf were manually measured and its area was estimated by multiplying length by width using a factor of 0.75, following McKee (1964). The Leaf Area Index (LAI) of each plant was then estimated by dividing its total leaf area by the available soil surface per plant. Samples were weighed after oven-drying at $70{ }^{\circ} \mathrm{C}$ (with circulating air) until constant weight.

At physiological maturity, maize cobs were manually harvested when they were ripe, from 11 to 13 September in 2007 and from 16 to 18 September in 2008, from the four central rows of each plot, covering $9.6 \mathrm{~m}^{2}$ $(4 \mathrm{~m} \times 2.4 \mathrm{~m})$. Grain and stover were separated, weighed, and aliquots (from three randomly selected plants) were dried at $70{ }^{\circ} \mathrm{C}$ to constant weight to determine their dry matter contents. Harvest index (HI) was calculated as Gr.Y in $\mathrm{t} \mathrm{ha}^{-1}$ divided by tDM in $\mathrm{t} \mathrm{ha} \mathrm{a}^{-1}$. The water con- 
tent of the upper $30 \mathrm{~cm}$ soil layer was monitored volumetrically, at five points in each plot, using a TDR probe at intervals of 2-3 days.

\section{Evaluation of the Hybrid-Maize model}

In simulations of maize growth and potential (fully irrigated) yields, when there is no need for estimates of irrigation requirements, inputs for three daily meteorological variables are required to run the Hybrid-Maize model: total solar radiation, and the maximum and minimum temperatures (T-high and T-low, respectively). In simulations of growth under an optimal water regime, according to estimates of irrigation requirements, or rain-fed conditions, data on three further daily variables - rainfall, relative humidity, and reference evapotranspiration (ET) - are needed (Yang et al., 2004, 2006). We obtained data for these variables (from 2005 to 2009) from an automatic weather station located at the Changwu experimental station, close to the field experimental sites.

Data acquired from the field experiments described above were used to calibrate and evaluate the HybridMaize model. In the calibration, cultivar coefficients were sequentially obtained, starting with the phenological parameters as dates of silking and maturity (Yang et al., 2004, 2006). A detailed description of the phenological development parameters used by the Hybrid-Maize model is presented in Table 1 . To evaluate the model, the LAI and biomass, yield and yield component outputs were compared to observed values, and mean prediction errors (MPEs) and normalized root mean square errors (RMSEs) were calculated following Loague and Green (1991) using Eqs. (1) and (2).

$\mathrm{MPE}=\frac{1}{n} \sum_{i=1}^{n}\left(O_{i}-P_{i}\right)$

RMSE $=\sqrt{\frac{\sum_{i=1}^{n}\left(P_{i}-O_{i}\right)^{2}}{n}} \times \frac{100}{M}$

where $P_{i}$ and $O_{i}$ are the predicted and observed values of the tested variables (e.g., LAI, biomass and soil water content), respectively, and $M$ is the mean of the observed variable. Normalized RMSE values provide a measure $(\%)$ of relative differences between simulated and observed data. A simulation is considered to be excellent, good, fair, and poor if the normalized RMSE is $<10 \%$, $\geq$ $10 \%$ but less than $20 \%, \geq 20 \%$ but less than $30 \%$, and $\geq 30 \%$, respectively (Jamieson et al., 1991).
For both the yield and yield components, percentage prediction deviations (PDs) were also calculated. Negative and positive deviations indicate under- and overprediction, respectively.

\section{Results}

\section{Evaluation of the Hybrid-Maize model - Phenologi-} cal development parameters

To calibrate the Hybrid-maize model, the phenological development parameters related to silking and maturity dates were used (see Table 1 for a detailed description of these parameters) obtained from the 2007 and 2008 field experiments. Significant between-treatment phenological variations of the crop in both years were detected. Irrigation resulted in rapid growth during the seedling and jointing stages, presumably because growth-promoting water conditions were maintained (Çakir, 2004). Hence, the silking stage was reached 6-7 days later in rain-fed plots than in irrigated plots, despite the thermal time $10{ }^{\circ} \mathrm{C}\left(\mathrm{TT}_{10}{ }^{\circ} \mathrm{C}\right)$ for the entire growth period (Total $\mathrm{TT}_{10}{ }^{\circ} \mathrm{C}$ ) in the two treatments being very similar (irrigated, $1414{ }^{\circ} \mathrm{C}$ in $2007,1387{ }^{\circ} \mathrm{C}$ in 2008 ; rain-fed, $1403{ }^{\circ} \mathrm{C}$ in $2007,1373{ }^{\circ} \mathrm{C}$ in 2008). This was presumably due to the better water conditions in irrigated plots. $\mathrm{The}^{\mathrm{TT}}{ }_{10}{ }^{\circ} \mathrm{C}$ from planting to silking ( $\mathrm{TT}_{10}{ }^{\circ} \mathrm{C}$ to silking) was much higher in rain-fed plots $\left(815^{\circ} \mathrm{C}\right.$ in 2007 and $813^{\circ} \mathrm{C}$ in 2008 , on average) than in irrigated plots $\left(742^{\circ} \mathrm{C}\right.$ in 2007 and $741{ }^{\circ} \mathrm{C}$ in 2008 , on average). The results suggested that the maize required more days to reach its required TT for silking under rain-fed conditions. Yields were also highly sensitive to the time of silking (Cassman et al., 2003), which highlights the importance of accurately specifying or estimating $\mathrm{TT}_{10}{ }^{\circ} \mathrm{C}$ to silking in order to obtain reliable yield estimates from maize growth models (Yang et al., 2004). Hence, in this study, simulations were based on the actual soil type, and actual crop sowing, silking, and physiological maturity dates under both irrigated and rain-fed conditions (Table 1); no further adjustments were made to model parameters and simulation results.

\section{Biomass and leaf area index (LAI) simulation}

The evaluation of the Hybrid-Maize model simulations of maize production using data from the 2007 and 2008 field experiments showed that there was good correspondence between simulated and observed biomass values under both irrigated and rain-fed conditions (Figure 2). The normalized RMSEs for this parameter were $16.80 \%$ and $17.15 \%$ for irrigated maize in 2007 and 2008 , respectively, with corresponding values of $20.32 \%$

Table 1 - Phenological development parameters used as inputs for the Hybrid-maize model.

\begin{tabular}{|c|c|c|c|c|c|}
\hline Experiment & Planting Date & Silking Date & Maturity Date & Total $\mathrm{TT}_{10}{ }^{\circ} \mathrm{C}$ & $\mathrm{TT}_{10^{\circ} \mathrm{C}}$ to silking \\
\hline & & - month, day - & 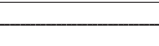 & & 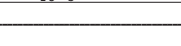 \\
\hline 2007 irrigated & $4-20$ & $7-10$ & $9-12$ & 1414 & 742 \\
\hline 2008 irrigated & $4-20$ & $7-12$ & $9-17$ & 1387 & 741 \\
\hline 2007 rain-fed & $4-20$ & 7-16 & $9-10$ & 1403 & 815 \\
\hline 2008 rain-fed & $4-20$ & 7-19 & $9-15$ & 1373 & 813 \\
\hline
\end{tabular}


and $21.88 \%$ for rain-fed maize (Figure 2). However, the MPEs were negative, for both years and for both irrigated and rain-fed conditions, this is presumably because of unavoidable competition from weeds and damage by insect pests during growth periods.

The Hybrid-maize model simulated LAI fairly well for both irrigated and rain-fed conditions. Normalized RMSE ranged from $11.08 \%$ to $22.06 \%$ for both years. The most accurate prediction for the maize in the 2008 was for the rain-fed plots (Figure 2). Good correspondence between simulated and observed LAI values was obtained for the maize in irrigated plots in 2007, and the rain-fed plots in 2007 and 2008, with normalized RMSEs ranging from $10 \%$ to $20 \%$. However, for the maize in the irrigated plots in 2008, LAI was only fairly well predicted, with a normalized RMSE of $22.06 \%$ (Figure 2).

\section{Simulation of yield and yield components}

Irrigation increased $(p<0.05)$ maize Gr.Y and tDM values, relative to the rain-fed treatment, by $31.3 \%$ and $28.0 \%$ in 2007, and by $36.4 \%$ and $29.3 \%$ in 2008, respectively. In addition, yield and yield components were accurately simulated by the Hybrid-Maize model for both years (Table 2). It simulated the Gr.Y and tDM of plants in irrigated plots very well, providing low PD values for both parameters $(-2.3 \%$ and $-5.7 \%$ for Gr.Y, $-5.2 \%$ and $-6.6 \%$ for tDM in 2007 and 2008, respectively). However, it over-predicted the Gr.Y and tDM of plants in rain-fed plots, giving higher PDs, ranging from $6.9 \%$ to $20.0 \%$. The hybrid-maize model might over predict, slightly, the plant Gr.Y and tDM when the crop experienced water deficit at it early growing stages. The PDs for HI were small in all cases, with values ranging from $-9.9 \%$ to $3.0 \%$.
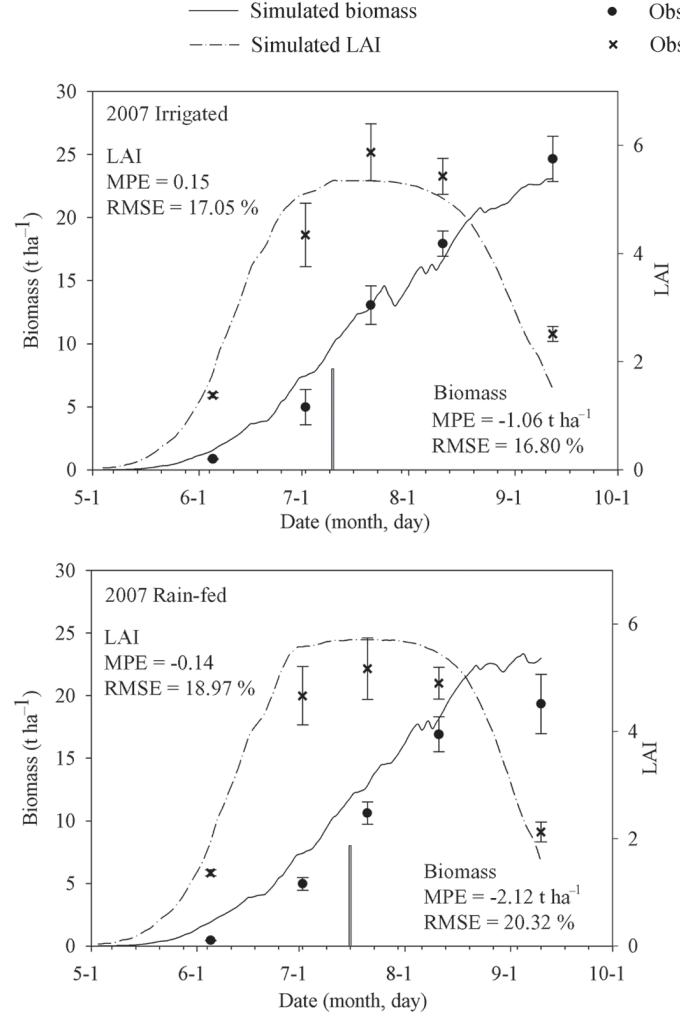

$\begin{array}{ll}- & \text { Observed biomass } \\ \times & \text { Observed LAI }\end{array}$
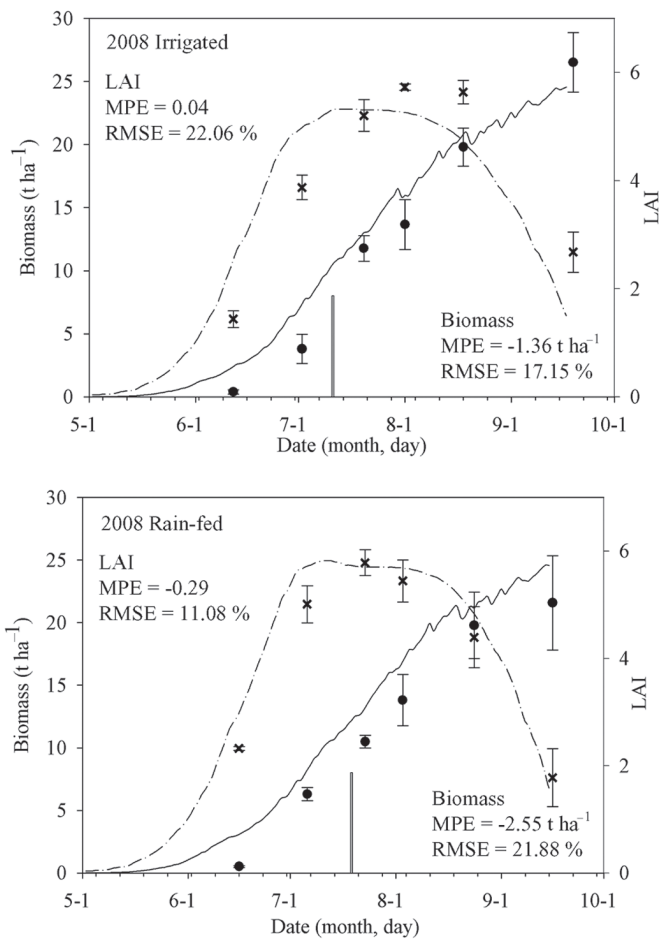

Figure 2 - Observed and simulated leaf area index (LAl) and biomass under irrigated and rain-fed conditions during the growth seasons in 2007 and 2008. Error bars of the observed values are twice the standard error of the mean; MPE = mean prediction errors; RMSE = root mean square errors.

Table 2 - Observed and simulated grain yield (Gr.Y), total aboveground biomass (tDM) and harvest index (HI) under rainfed and irrigated conditions during the growth seasons in 2007 and 2008.

\begin{tabular}{|c|c|c|c|c|c|c|c|c|c|}
\hline \multirow{2}{*}{ Experiment } & \multicolumn{2}{|c|}{ Gr.Y (t ha-1) } & \multirow{2}{*}{$\begin{array}{c}\text { PD } \\
\%\end{array}$} & \multicolumn{2}{|c|}{ tDM (t ha-1) } & \multirow{2}{*}{$\begin{array}{c}\text { PD } \\
\%\end{array}$} & \multicolumn{2}{|c|}{$\mathrm{HI}$} & \multirow{2}{*}{$\begin{array}{l}\mathrm{PD} \\
\%\end{array}$} \\
\hline & Simulated & Observed & & Simulated & Observed & & Simulated & Observed & \\
\hline 2007 irrigated & 12.3 & $12.6 \pm 0.8$ & -2.3 & 23.4 & $24.7 \pm 1.8$ & -5.2 & 0.53 & $0.51 \pm 0.02$ & 3.0 \\
\hline 2008 irrigated & 12.8 & $13.5 \pm 1.5$ & -5.7 & 24.8 & $26.5 \pm 3.4$ & -6.6 & 0.52 & $0.51 \pm 0.03$ & 1.0 \\
\hline 2007 rain-fed & 10.3 & $9.6 \pm 0.8$ & 6.9 & 22.9 & $19.3 \pm 2.4$ & 18.6 & 0.45 & $0.50 \pm 0.03$ & -9.9 \\
\hline 2008 rain-fed & 11.1 & $9.9 \pm 1.2$ & 11.7 & 24.6 & $20.5 \pm 3.8$ & 20.0 & 0.45 & $0.48 \pm 0.04$ & -7.0 \\
\hline
\end{tabular}

Observed values are given as means \pm standard error of means $(n=4)$. 


\section{Soil water content simulation}

The water content in the soil profile of the irrigated plots was maintained at $70-85 \%$ of the field water capacity (FWC) in both 2007 and 2008 to ensure that the crops received adequate water supplies throughout the entire growing season (Figure 3). In addition, the simulated soil water content data (for the 0-30 cm layer) agreed well with observed values, with normalized RMSEs of 19.45 $\%$ and $11.03 \%$ for 2007 and 2008, respectively.

Soil water content was very well simulated for the rain-fed experiment and low values were obtained for the normalized RMSE (normalized RMSE $<20 \%$ ). The seasonal variation in soil water content for the rain-fed experiment showed several differences when compared

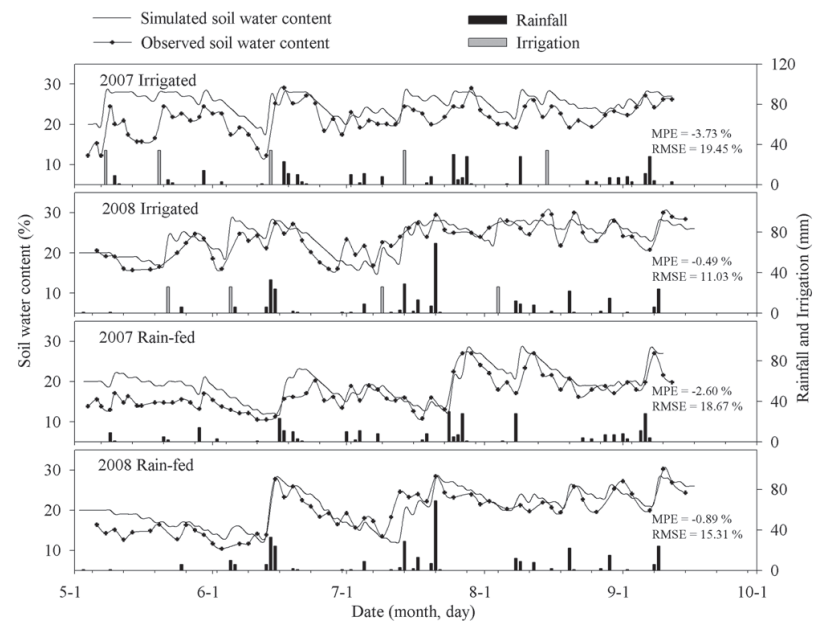

Figure 3 - Observed and simulated soil water content under irrigated and rain-fed conditions during the growth seasons in 2007 and 2008. to the irrigated experiment. It was generally low at the crop seedling stage (during May and the first half of June) because high soil evaporation removed water from the upper soil profile, and increased after the jointing stage (from mid-June to July) due to precipitation and enhanced canopy shading (Figure 3).

\section{Analysis of yield determinants in past cropping seasons}

The field experiment results presented betweentreatment variations in the phenological development of the crop in both 2007 and 2008 (Table 1). In the simulations we used mean values of total $\mathrm{TT}_{10{ }^{\circ} \mathrm{C}}$ and $\mathrm{TT}_{10}{ }^{\circ} \mathrm{C}$ to silking for irrigated and rain-fed conditions, calculated from the results of the field experiments in 2007 and 2008. Standard practices in the area are: planting around April 20 with 0.6 $\mathrm{m}$ row spacing and a final population of 85,000 plants ha ${ }^{-1}$. Pioneer 335 hybrids grown in this environment require $1400 \mathrm{TT}_{10}{ }^{\circ} \mathrm{C}$ and $742 \mathrm{TT}_{10}{ }^{\circ} \mathrm{C}$ from planting to maturity and from planting to silking, respectively, under full irrigated conditions, with corresponding requirements of $1388 \mathrm{TT}_{10}{ }^{\circ} \mathrm{C}$ and $814 \mathrm{TT}_{10}{ }^{\circ} \mathrm{C}$ under rain-fed conditions.

Under irrigated conditions, the model predicts an average yield potential of about $11.53 \mathrm{t} \mathrm{ha}^{-1}$, ranging from 10.56 to $12.93 \mathrm{t} \mathrm{ha}^{-1}$ during the 5 -year period for which weather data are available (Table 3). The average temperature during the grain-filling period (rTmean) was $20.7{ }^{\circ} \mathrm{C}$, and the lowest predicted yield was for 2006, when the rTmean was considerably higher $\left(23.1^{\circ} \mathrm{C}\right)$. In contrast, the highest predicted yield was in 2008, when the rTmean was only $19.5^{\circ} \mathrm{C}$, hence both the grain-filling and total growth (vegetative + reproductive) periods were long (68 and 142 days, respectively). These results indicate that high temperatures during the reproductive, grain-filling stages may reduce potential yields under currently recommended

Table 3 - Simulated grain yield, total aboveground biomass, harvest index and environmental factors computed for the total growing season (t), the vegetative (v) or reproductive ( $r$ ) stages under irrigated and rain-fed conditions for the years from 2005 to 2009.

\begin{tabular}{|c|c|c|c|c|c|c|c|c|c|c|c|}
\hline Year & Gr.Y & tDM & $\mathrm{HI}$ & vDays & rDays & $V+R$ & tSola & Tmean & vTmean & rTmean & tRain \\
\hline \multicolumn{12}{|c|}{ Irrigated } \\
\hline 2005 & 11.58 & 22.77 & 0.51 & 73 & 57 & 130 & 2359 & 20.4 & 19.6 & 21.5 & 313 \\
\hline 2006 & 10.56 & 21.84 & 0.48 & 72 & 50 & 122 & 2273 & 21.1 & 19.8 & 23.1 & 155 \\
\hline 2007 & 11.76 & 23.12 & 0.51 & 70 & 61 & 131 & 2315 & 20.4 & 20.2 & 20.6 & 299 \\
\hline 2008 & 12.93 & 25.05 & 0.52 & 74 & 68 & 142 & 2688 & 19.6 & 19.6 & 19.5 & 328 \\
\hline 2009 & 10.82 & 21.47 & 0.5 & 73 & 75 & 148 & 2231 & 19.2 & 19.6 & 18.8 & 370 \\
\hline mean & 11.53 & 22.85 & 0.5 & 72 & 62 & 135 & 2373 & 20.1 & 19.8 & 20.7 & 293 \\
\hline \multicolumn{12}{|c|}{ Rain-fed } \\
\hline 2005 & 9.38 & 21.91 & 0.43 & 79 & 50 & 129 & 2342 & 20.4 & 19.8 & 21.4 & 313 \\
\hline 2006 & 8.59 & 20.84 & 0.41 & 77 & 44 & 121 & 2270 & 21.2 & 20 & 23.1 & 155 \\
\hline 2007 & 9.84 & 22.51 & 0.44 & 75 & 54 & 129 & 2279 & 20.4 & 20.3 & 20.6 & 299 \\
\hline 2008 & 11.26 & 24.98 & 0.45 & 81 & 60 & 141 & 2678 & 19.6 & 19.6 & 19.5 & 328 \\
\hline 2009 & 9.44 & 19.7 & 0.48 & 79 & 67 & 146 & 2193 & 19.2 & 19.8 & 18.5 & 370 \\
\hline mean & 9.70 & 21.99 & 0.44 & 78 & 55 & 133 & 2352 & 20.2 & 19.9 & 20.6 & 293 \\
\hline
\end{tabular}

Gr.Y = grain yield (or grain dry matter), $\mathrm{t} \mathrm{ha}{ }^{-1} ; \mathrm{tDM}=$ total aboveground dry matter (leaves, stalks, cobs, grain), $\mathrm{t}$ ha ${ }^{-1} ; \mathrm{HI}=\mathrm{harvest}$ index (grain dry matter/total aboveground dry matter); vDays = days from emergence to silking (i.e., length of vegetative stage); rDays = days from silking to maturity (i.e., length of reproductive stage); $\mathrm{V}+\mathrm{R}=$ days from emergence to maturity (i.e., total length of growing period); tSola = total cumulative solar radiation from emergence to maturity, Langley or $\mathrm{MJ} \mathrm{m}^{-2}$; Tmean = mean daily average temperature from emergence to maturity, ${ }^{\circ} \mathrm{C}$; vTmean = mean daily average temperature from emergence to silking, ${ }^{\circ} \mathrm{C}$; $\mathrm{rTmean}=$ mean daily average temperature from silking to maturity, ${ }^{\circ} \mathrm{C}$; tRain = total rainfall from emergence to maturity, mm. 
planting regimes, and are consistent with the findings by Muchow et al. (1990) that low temperatures increase maize yields by prolonging the time that plants can intercept radiation. Similarly, Badu-Apraku et al. (1983) found that low temperatures increase the duration of the grain-filling phase, which is often correlated with Gr.Y. The simulated potential yield for 2009 was $10.82 \mathrm{t} \mathrm{ha}^{-1}$ under irrigated conditions; significantly lower than the average yield with similar management. This may have been because the total incident solar radiation during the growing season in 2009 amounted to $2231 \mathrm{MJ} \mathrm{m}^{-2}, 142 \mathrm{MJ} \mathrm{m}^{-2}$ less than the 5-yr average, and was particularly low during the grain-filling period (data not shown). Werker and Jaggard (1998) and Lecoeur and Ney (2003) have shown that the abundance of dry matter produced by crops when conditions are nonlimiting, is almost linearly correlated to the photosynthetically active solar radiation (PAR) intercepted by their green leaves.

According to the simulations, during 2005-2009, under rain-fed conditions attainable yields averaged $9.7 \mathrm{tha}^{-1}$, ranging from 8.59 to $11.26 \mathrm{t} \mathrm{ha}^{-1}$ at the Changwu experimental station, and the average rain-fed yield was 1.83 $\mathrm{t} \mathrm{ha}^{-1}$ less than the average potential yield with irrigation (Table 3). In these years the rainfall during the growing season (tRain) varied from $155 \mathrm{~mm}$ in 2006 to $328 \mathrm{~mm}$ in 2008 (when simulated yields were lowest and highest, respectively). However, although rainfall during the growing season (tRain) was also high in 2009 (tRain $=370 \mathrm{~mm}$ ), the Gr.Y was rather low, probably largely due to the lower solar radiation for 2009 .

\section{Analysis of soil moisture status under rain-fed condition}

Potential maize yields on the Loess Plateau are high because of the moderate elevation (about 1,200 m), high solar radiation and a generally dry climate. Provided that crops can be well irrigated, adequate quantities of nutrients can be supplied to meet crop requirements, and pests can be controlled. Mean annual rainfall amounts to ca. $578 \mathrm{~mm}$, but varies strongly from year to year.

To evaluate the severity of water stress in this region, we simulated the soil moisture status without irrigation, based on actual rainfall and ET data. Rainfall, soil moisture, and the crop water stress coefficients for the years from 2005 to 2009 are shown in Figure 4. Rainfall during the growing season averaged $290 \mathrm{~mm}$, it was unevenly distributed, water deficits occurred during the crop growth period every year, and (as shown in the simulations, see Table 3) yields from rain-fed plots were lower and considerably more variable than those from irrigated plots. The results indicate that water stress may cause substantial yield losses. 2006 was a dry, hot year in many parts of the Loess Plateau (Figure 4), six periods of moisture stress affected crop growth and development, and yields were significantly reduced due to a lack of rainfall during the growing season, particularly during the reproductive growth stage. High temperatures during grain-filling may also have contributed to low yields in that year.

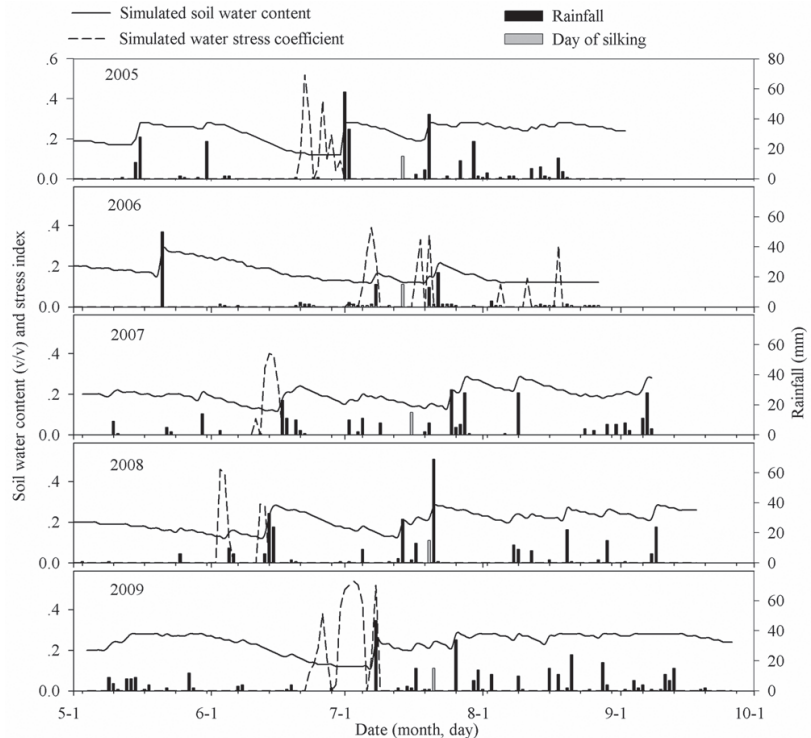

Figure 4 - Rainfall events and their effects on predicted soil water contents and water stress coefficient under rain-fed conditions for the years from 2005 to 2009 .

\section{Discussion}

Accurate information on the time to silking is essential for reliable Gr.Y predictions (Yang et al., 2004). In CERES-Maize, the model requires inputs for two parameters to predict the time of silking, both of which are difficult to measure and unavailable for most commercial hybrids (Jones and Kiniry, 1986; Jones et al., 2003). In contrast, Hybrid-Maize requires only one hybrid-specific parameter to simulate aboveground phenological development as defined by tassel initiation, silking, grain filling, and physiological maturity. In fact, however, in both experimental seasons (2007 and 2008) in this study, the irrigated treatment significantly advanced maize silking, and markedly increased the durations of the reproductive stage compared to the rain-fed treatment. Therefore, using actual planting, silking and maturity dates in our study, the Hybrid-Maize model was able to accurately simulate yield and yield components of the maize growing at our experimental site on the Loess Plateau.

The model also simulated LAI, total biomass and soil water contents reasonably well, especially for irrigated conditions. However, there was a certain overestimation of the biomass, although there was no significant difference between the simulated and observed values. Similar findings have been observed in other studies where crop simulation models have been used to determine regional yields (Grassini et al., 2009). This is presumably because unavoidable competition by weeds, and damage by insect pests, during growth periods inhibit the growth and development of maize in the field, and hence decrease the observed biomass values.

Relative to the rain-fed treatment, irrigation increased $(p<0.05)$ the maize Gr.Y and tDM. This was because the improvements in water status provided by 
irrigation often result in taller, more robust plants, larger leaf areas (NeSmith and Ritchie, 1992), and increases in vegetative dry matter (Claassen and Shaw, 1970), and promote the emergence of leaf tips and tassels, silking, and the onset of grain-filling (NeSmith and Ritchie, 1992). Supplying sufficient water during reproductive stages (after silking) can also reduce the period between silking and pollen shedding (Herrero and Johnson, 1981) and prolong the grain-filling period (Westgate, 1994).

The Hybrid-Maize model is a promising tool for analyzing yield determinants in previous cropping seasons. The analysis of yield determinants with the model indicated that its explanatory power is increased by using separate sets of meteorological data for the vegetative and reproductive stages rather than estimates for the whole growing season. Applying this approach, potential yields of aboveground biomass were found to be highest in years with long growing seasons. High cumulative solar radiation and warm temperatures during vegetative growth phases are also correlated with high potential biomass yields-presumably due to associated increases in photosynthetic rates and/or the speed of leaf area expansion, which determines the timing of canopy closure (Liu et al., 2010a).

Further research is required to develop and apply this modeling approach to make practical recommendations for the field management of maize growing in different locations. Further calibration and evaluation of the model may also be required to adjust to the frequent changes in varieties used by farmers.

\section{Conclusion}

The Hybrid-Maize model accurately simulated LAI, biomass, and soil water data from the field experiments in both 2007 and 2008 years. Gr.Y as well as yield components were also accurately simulated. Highest potential Gr.Y are expected at locations where the length of the post-silking phase is maximized, keeping temperatures over the optimum range for kernel growth and carbon net assimilation. Substantial potential yield may have been lost due to water stress under rain-fed conditions. This information should be useful for both farmers and decision-makers.

\section{Acknowledgements}

This work was financially supported by the NSFC (31100386), the NSF of Hubei Province, China (2010CDB10502), and the Cooperated Program with International Plant Nutrition Institute (IPNI-HB-33).

\section{References}

Azam-Ali, S.N.; Crout, N.M.J.; Bradley, R.G. 1994. Perspectives in modeling resource capture by crops. p. 125-148. In: Monteith, J.L.; Scott, R.K.; Unsworth, M.H., eds. Resource capture by crops. Nottingham University Press, Nottingham, UK.
Badu-Apraku， B.; Hunter, R.B.; Tollenaar, M. 1983. Effect of temperature during grain filling on whole plant and grain yield in maize (Zea mays L.). Canadian Journal of Plant Science 63: 357-363.

Çakir, R. 2004. Effect of water stress at different development stages on vegetative and reproductive growth of corn. Field Crops Research 89: 1-16.

Cassman, K.G.; Dobermann, A.; Walters, D.T.; Yang, H.S. 2003. Meeting cereal demand while protecting natural resources and improving environmental quality. Annual Review of Environment and Resources 28: 315-358.

Cirilo, A.G.; Andrade, F.H. 1994. Sowing date and maize productivity. I. Crop growth and dry matter partitioning. Crop Science 34: 1039-1043.

Claassen, M.M.; Shaw, R.H. 1970. Water deficit effects on corn. I. Vegetative components. Agronomy Journal 62: 649-652.

Duncan, W.G.; Shaver, D.L.; Williams, W.A. 1973. Insolation and temperature effects on maize growth and yield. Crop Science 13: 187-191.

Duvick, D.N.; Cassman, K.G. 1999. Post-green revolution trends in yield potential of temperate maize in the North-Central United Sates. Crop Science 39: 1622-1630.

Grassini, P.; Yang, H.S.; Cassman, K.G. 2009. Limits to maize productivity in Western Corn-Belt: a simulation analysis for fully irrigated and rainfed conditions. Agricultural and Forest Meteorology 149: 1254-1265.

Herrero, M.P.; Johnson, R.R. 1981. Drought stress and its effects on maize reproductive systems. Crop Science 21: 105-110.

Jamieson, P.D.; Porter, J.R.; Wilson, D.R. 1991. A test of the computer simulation model ARC-WHEAT1 on wheat crops grown in New Zealand. Field Crops Research 27: 337-350.

Jones, C.A.; Kiniry, J.R. 1986. CERES-Maize: A Simulation Model of Maize Growth and Development. Texas A\&M University Press, College Station, TX, USA.

Jones, J.W.; Hoogenboom, G.; Porter, C.H.; Boote, K.J.; Batchelor, W.D.; Hunt, L.A.; Wilkens, P.W.; Singh, U.; Gijsman, A.J.; Ritchie, J.T. 2003. The DSSAT cropping system model. European Journal of Agronomy 18: 235-265.

Kang, S.Z.; Zhang, L.; Liang, Y.L.; Hu, X.T.; Cai, H.J.; Gu, B.J. 2002. Effects of limited irrigation on yield and water use efficiency of winter wheat in the Loess Plateau of China. Agricultural Water Management 55: 203-216.

Lecoeur, J.; Ney, B. 2003. Change with time in potential radiationuse efficiency in field pea. European Journal of Agronomy 19: 91-105.

Li, S.; Xiao, L. 1992. Distribution and management of drylands in the People's Republic of China. Advances in Soil Sciences18: 148-293.

Liu, Y.; Yang, S.J.; Li, S.Q.; Chen, X.P.; Chen F. 2010a. Growth and development of maize (Zea mays $L$ ) in response to different field water management practices: resource capture and use efficiency. Agricultural and Forest Meteorology 150: 606-613.

Liu, Y.; Li, S.Q.; Chen, F.; Yang, S.J.; Chen X.P. 2010b. Soil water dynamics and water use efficiency in spring maize (Zea mays L) fields subjected to different water management practices on the Loess Plateau, China. Agricultural Water Management 97: 769-775. 
Lizaso, J.I.; Batchelor, W.D.; Adams, S.S. 2001. Alternate approach to improve kernel number calculation in CERES-Maize. Transactions of the ASAE. 44: 1011-1018.

Loague, K.; Green, R.E. 1991. Statistical and graphical methods for evaluating solute transport models: overview and application. Journal of Contaminant Hydrology 7: 51-73.

Löffler, C.M.; Wei, J.; Fast, T.; Gogerty, J.; Langton, S.; Bergman, M.; Merrill, B.; Cooper, M. 2005. Classification of maize environments using crop simulation and geographic information systems. Crop Science 45: 1708-1716.

McKee, G.W. 1964. A coefficient for computing leaf area in hybrid corn. Agronomy Journal 56: 240-241.

Muchow, R.C.; Sinclair, T.R.; Bennet, J.M. 1990. Temperature and solar radiation effects on potential maize yield across locations. Agronomy Journal 82: 338-343.

NeSmith, D.S.; Ritchie, J.T. 1992. Short- and long-term responses of corn to a pre-anthesis soil water deficit. Agronomy Journal 84: 107-113.

Pedersen, P.; Boote, K.J.; Jones, J.W.; Lauer, J.G. 2004. Modifying the CROPGRO-Soybean model to improve predictions for the upper Midwest. Agronomy Journal 96: 556-564.

Sadler, E.J.; Gerwig, B.K.; Evans, D.E.; Busscher, W.J.; Bauer, P.J. 2000. Site-specific modeling of corn yield in the SE coastal plain. Agricultural Systems 64: 189-207.

Sau, F.; Boote, K.J.; Bostick, W.M.; Jones, J.W.; Minguez, M.I. 2004. Testing and improving evapotranspiration and soil water balance of the DSSAT crop models. Agronomy Journal 96: 1243-1257.

Tojo Soler, C.M.; Sentelhas, P.C.; Hoogenboom, G. 2007. Application of the CSM-CERES-Maize model for planting date evaluation and yield forecasting for maize grown off-season in a subtropical environment. European Journal of Agronomy 27: 165-177.
Tollenaar, M.; Lee, E.A. 2002. Yield potential, yield stability and stress tolerance in maize. Field Crops Research 75: 161-169.

Wang, Y.J.; Xie, Z.K.; Malhi, S.S.; Vera, C.L.; Zhang, Y.B.; Wang, J.N. 2009. Effects of rainfall harvesting and mulching technologies on water use efficiency and crop yield in the semiarid Loess Plateau, China. Agricultural Water Management 96: 374-382.

Werker, A.R.; Jaggard, K.W. 1998. Dependence of sugar beet yield on light interception and evapotranspiration. Agricultural and Forest Meteorology 89: 224-240.

Westgate, M.E. 1994. Water status and development of the maize endosperm and embryo during drought. Crop Science 34: 7683.

Xue, J.Q.; Zhang, R.H.; Li, F.Y.; Zhang, X.H. 2008. Current status, problem and strategy of maize breeding in Shannxi Province. Journal of Maize Science 16: 139-141 (in Chinese, with abstract in English).

Yang, H.S.; Dobermann, A.; Cassman, K.G.; Walters, D.T. 2006. Hybrid-Maize (ver. 2006). A Simulation Model for Corn Growth and Yield. Nebraska Cooperative Extension CD 9, University of Nebraska-Lincoln, Lincoln, NE, USA. Available at: http:// www.hybridmaize.unl.edu/ [Accessed Nov. 25, 2010]

Yang, H.S.; Dobermann, A.; Lindquist, J.L.; Walters, D.T.; Arkebauer, T.J.; Cassman, K.G. 2004. Hybrid-maize: a maize simulation model that combines two crop modeling approaches. Field Crops Research 87: 131-154.

Zhang, S.L.; Lövdahl, L.; Grip, H.; Tong, Y.A.; Yang, X.Y.; Wang, Q.J. 2009. Effects of mulching and catch cropping on soil temperature, soil moisture and wheat yield on the Loess Plateau of China. Soil and Tillage Research 102: 78-86. 